\title{
AB INITIO AND DENSITY FUNCTIONAL STUDIES OF COOPERATIVE HYDROGEN BONDING IN CALIX[4]- AND CALIX[6]ARENES
}

\author{
A. N. Novikov, V. A. Bacherikov, Yu. E. Shapiro, \\ and A. I. Gren
}

UDC 541.63:547.298.11/.16

\begin{abstract}
The cone conformation of $C_{4}$ symmetry is shown by the Hartree-Fock method (3-21G basis) to be the predominant conformer of calix[4]arene; the compressed cone of $C_{2}$ symmetry is the major conformer of calix[6]arene. Using quantum chemical methods we calculated hydrogen bond cleavage energies for calix[4]- (ab initio and density functional methods) and calix[6]arene (ab initio), and also for the complex of calix[4]arene with carbon disulfide. These energies along with structural data point to the cooperative effect of hydrogen bonds. The results of these studies provided an explanation to the greater conformational lability of calix[6]arene compared with calix[4]arene molecules. It is also predicted that the nucleophilic substitution reaction involving calix[6]arene in the presence of weak bases and in aprotic solvents, as well as in the gas phase, will occur via diastereomeric transition states.
\end{abstract}

Keywords: calix[4]arene, calix[6]arene, $a b$ initio and density functional methods, hydrogen bond, cooperative effect, compressed cone conformer.

In recent years, experimental and theoretical publications on calix[4]- and calix[6]arenes [1-11] have increased in number. These compounds along with crown ethers are useful in modeling molecular recognition processes and in studies of molecular and ion transfer across cell membranes [10]. A few works are devoted to studies of calix[4]arenes and thiacalix[4]arenes by ab initio [7-9,12,13] and density functional [6-9,14] methods, and only one work deals with investigation of calix[6]arenes by these methods [13]. None of these works dealing with calixarenes has reported on hydrogen bond energy calculations, although this energy is the key factor of conformational stability and conformational lability of calixarenes with free hydroxyl groups [12] and their reactivity [11].

The stability of the hydrogen bond in calixarene was correlated with the reaction route involving this compound when dialkoxydihydroxycalix[4]arene was synthesized from monoalkoxytrihydroxycalix[4]arene [11] (Fig. 1). Similar alkylation and acylation reactions with intermediate phenoxide anions stabilized by the maximum number of stable hydrogen bonds were also reported for calixarenes having larger rings [11]. In his review [11] D. Rudkevich demonstrated in detail that intramolecular hydrogen bonds are as important as intermolecular hydrogen bonds for molecular void formation. Therefore further investigation of intramolecular hydrogen bonding in "guest-host" complexes (in particular, investigation of the energy parameters of hydrogen bonds) is of great importance in view of the influence of intramolecular hydrogen bonds on the route and rate of transformations involving cleavage and formation of covalent bonds and on the complexation ability of cavitands.

I. I. Mechnikov Odessa National University; andrej_novikov@mail.ru, andrej_novikov@ukr.net. Translated from Zhurnal Strukturnoi Khimii, Vol. 47, No. 6, pp. 1015-1027, November-December, 2006. Original article submitted July 13, 2005; revised April 18, 2006. 


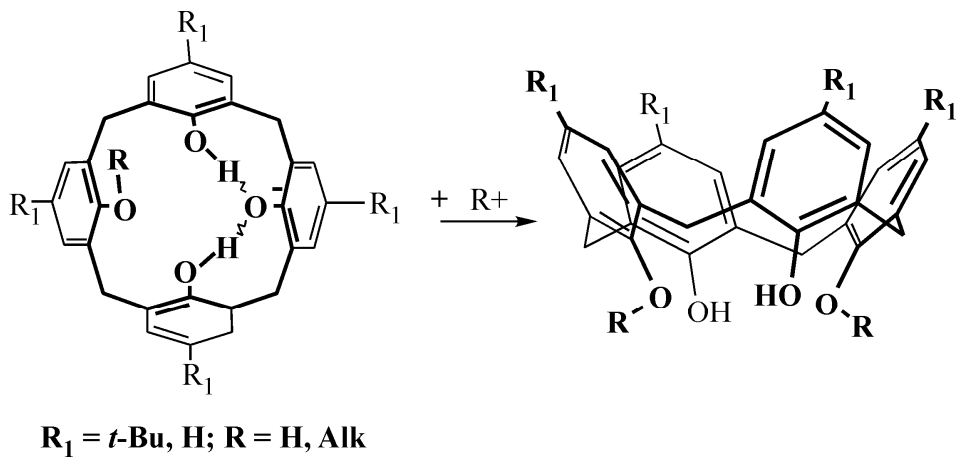

Fig. 1. Alkylation of tetrahydroxycalix[4]arene and monoalkoxytrihydroxycalix[4]arene.

The purpose of the present work is to evaluate hydrogen bonding ( $\mathrm{H}$ bonding) in specific cooperative systems of calix[4]- and calix[6]arenes that are due to the formation of intramolecular hydrogen bonds ( $\mathrm{H}$ bonds) in the ring. The hydrogen bond of these cyclic compounds may be evaluated by using the energy of proton elimination from the oxygen atom, which is proton donor in the given hydrogen bond. The $\mathrm{H}$ bond of this type may also be characterized in terms of the cooperative effect of $\mathrm{H}$ bonds, increasing with the length of the chain. These quantities were evaluated by the technique suggested by P. Grootenhuis [1] based on the results of geometry optimization by several ab initio methods.

The parameters of $\mathrm{O}-\mathrm{H} . . . \mathrm{O}$ hydrogen bonds are the following $[15,16]$ : 1) distances between oxygen atoms; 2) angles formed by the atoms of the $\mathrm{O}-\mathrm{H} . . . \mathrm{O}$ system; 3) hybridization of the oxygen atom that is proton acceptor or donor of the lone electron pair; 4) mutual orientation of the orbitals of the lone electron pair and $\mathrm{O}-\mathrm{H}$ bond and accordingly the efficiency of the overlap of these orbitals during the formation of a strong hydrogen bond; 5) hydrogen bond energy; 6) size of the ring with the hydrogen bond in question in the case of intramolecular hydrogen bonds. For calix[4]arenes, hydrogen bonding may also depend on the nature of the para-substituents and accordingly on the mutual orientation of the benzene rings, which is largely determining for the void shape in calixarene.

The results of geometry optimization were shown to be in good agreement [17] for H bond lengths and angles of D(+)-glyceraldehyde and dihydroxyacetone; RHF/3-21G and MP2/6-31G $(d, p)$ methods gave better agreement than RHF/6$31 \mathrm{G}(d, p)$ and MP2/6-31G $(d, p)$. Since 3-21G is the simplest (split valence-shell) basis that does not require much computing effort for complex molecular systems, it seemed interesting to perform also a series of calculations for conformers of calix[4]arene using several $a b$ initio and density functional methods with the $3-21 \mathrm{G}$ basis.

\section{CALCULATION PROCEDURE}

Conformation analysis of calix[6]arene was carried out by the restricted Hartree-Fock method using the 3-21G basis. Conformation analysis of calix[4]arene was performed by the RHF/STO-2G and RHF/3-21G methods and by density functional methods using Becke's one- and three-parameter exchange functionals (B and B3 [18]), or using Gill's exchange potential G96 [19] combined with the Lee-Yang-Parr (LYP) correlation functionals [20] G96LYP/3-21G, B3LYP/6-31G, and $\mathrm{B} 3 \mathrm{LYP} / 6-31 \mathrm{G}(d, p)$. For the cone conformer of calix calix[4]arene, calculations were also performed by density functional methods using Perdew-Burke-Ernzerhof's CPBE96 correlation and PBE96 exchange correlation functionals [21].

To evaluate hydrogen bond parameters for major conformations of calix[4]arene (Fig. $2 a$, compound I, $C_{4 v}$ cone), its monoanion II, calix[6]arene (Fig. $2 b$, compound III, $C_{2 v}$ compressed cone), its monoanions IV, V, and VI, and calix[4]arene complex with carbon disulfide (supramolecular compound VII), in this work we performed optimization of the $C_{4 v}$ cone conformation of compound I by the Hartree-Fock method (RHF, ab initio) using STO-3G, 3-21G $(d, p)$, 6-31G, and 6-31G $(d)$ basis sets and by the density functional theory (DFT) method using Becke's exchange functional (B) and Lee-Yang-Parr (LYP) correlation functional in 3-21G and 6-31G basis sets (in the latter case, calculation was carried out neglecting and 

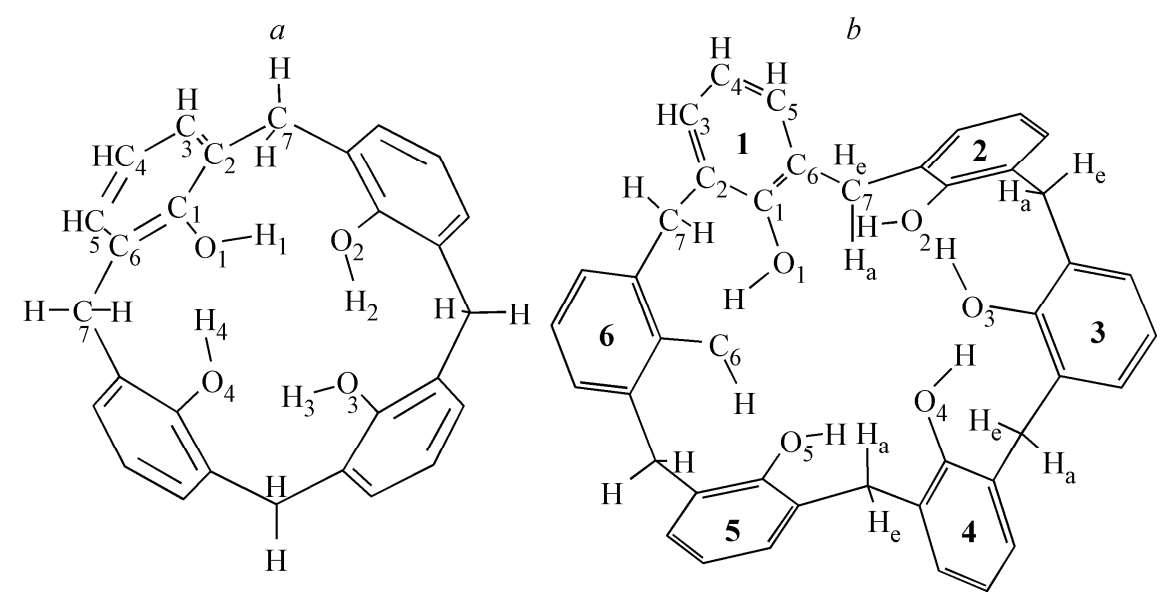

Fig. 2. Preferable conformers of calix[4]arene and calix[6]arene: $a-C_{4 v}$ cone conformer of calix[4]arene, $b-C_{2 v}$ compressed cone conformer of calix[6]arene.

TABLE 1. Structural Parameters of the Cone Conformer of Calix[4]arene

\begin{tabular}{c|c|c|c|c|c|c|c|c}
\hline \multirow{2}{*}{$\begin{array}{c}\text { Bond length, } \AA, \\
\text { angle, deg }\end{array}$} & \multicolumn{2}{|c}{ Calculation procedure } \\
\cline { 2 - 8 } & $\begin{array}{c}\text { RHF/STO- } \\
2 \mathrm{G}\end{array}$ & $\begin{array}{c}\text { RHF/STO- } \\
3 \mathrm{G}\end{array}$ & RHF/3-21G & $\begin{array}{c}\text { RHF/3- } \\
21 \mathrm{G}(d, p)\end{array}$ & RHF/6-31G & $\begin{array}{c}\text { RHF/6- } \\
31 \mathrm{G}(d)\end{array}$ & RHF/PM3 & Experiment \\
\hline $\mathrm{C}_{1}-\mathrm{C}_{2}$ & 1.416 & 1.401 & 1.388 & 1.388 & 1.394 & 1.393 & 1.410 & 1.384 \\
$\mathrm{C}_{1}-\mathrm{C}_{6}$ & 1.417 & 1.402 & 1.389 & 1.388 & 1.393 & 1.394 & 1.409 & 1.409 \\
$\mathrm{C}_{2}-\mathrm{C}_{3}$ & 1.401 & 1.390 & 1.386 & 1.387 & 1.392 & 1.390 & 1.394 & 1.392 \\
$\mathrm{C}_{2}-\mathrm{C}_{7}$ & 1.544 & 1.537 & 1.526 & 1.529 & 1.526 & 1.527 & 1.502 & 1.527 \\
$\mathrm{C}_{1}-\mathrm{O}_{1}$ & 1.390 & 1.391 & 1.387 & 1.397 & 1.384 & 1.364 & 1.368 & 1.384 \\
$\mathrm{O}_{i} \ldots \mathrm{O}_{i+1}$ & 2.426 & 2.410 & 2.571 & 2.633 & 2.651 & 2.739 & 3.094 & 2.640 \\
$\mathrm{C}_{1}-\mathrm{C}_{2}-\mathrm{C}_{3}$ & 118.6 & 118.5 & 118.4 & 118.1 & 117.7 & 117.7 & 118.7 & 117.3 \\
$\mathrm{C}_{1}-\mathrm{C}_{2}-\mathrm{C}_{7}$ & 121.4 & 121.6 & 121.5 & 121.9 & 122.4 & 122.6 & 121.9 & 121.9 \\
$\mathrm{C}_{1}-\mathrm{C}_{6}-\mathrm{C}_{7}$ & 120.1 & 120.2 & 120.7 & 121.1 & 121.4 & 121.4 & 122.5 & 117.1 \\
$\mathrm{C}_{2}-\mathrm{C}_{7}-\mathrm{C}_{6}$ & 113.7 & 113.3 & 111.9 & 111.6 & 113.6 & 113.4 & 110.4 & 108.2 \\
$\mathrm{C}_{2}-\mathrm{C}_{1}-\mathrm{C}_{6}$ & 120.4 & 120.8 & 121.5 & 122.1 & 122.4 & 122.0 & 120.9 & 121.6 \\
$\mathrm{O}_{1}-\mathrm{C}_{1}-\mathrm{C}_{2}$ & 122.0 & 121.7 & 121.1 & 120.9 & 121.0 & 121.3 & 122.4 & 119.1 \\
$\mathrm{O}_{1}-\mathrm{C}_{1}-\mathrm{C}_{6}$ & 117.6 & 117.5 & 117.4 & 117.1 & 116.7 & 116.7 & 116.7 & 123.7
\end{tabular}

including polarization functions on all atoms); optimization of the $C_{2 v}$ compressed cone conformer of compound III and structure optimization of compound VII were performed by the Hartree-Fock method in STO-2G, 3-21G, and 6-31G basis sets. The optimized structural parameters of the basic conformers of compounds I and III are presented in Tables 1, 2, and 3, respectively (the spatial structures are shown in Figs. $2 a$ and $2 b$, respectively); the energy parameters of all conformers of compound I are given in Table 4. Moreover, geometry optimization of the model monoanions of these compounds in cone conformations was carried out by the above-mentioned $a b$ initio methods with respective basis sets. To allow for electron correlation we also performed additional refinement of the energy quantities of hydrogen bonds in the dominant conformers of compound I and its monoanion and refined the energy parameters of phenol and its monoanion by the second order Möller-Plesset method (Table 5).

Moreover, RHF/3-21G and RHF/6-31G quantum chemical calculations were performed for $\mathrm{CS}_{2}$ to evaluate changes in the structural parameters of the $\mathrm{CS}_{2}$ molecule due to its complexation with calix[4]arene. To compare the HOMOs of calixarenes with those of ordinary nucleophiles we also calculated the HOMOs of benzene, aniline, dimethylaminobenzene, nitrobenzene, phenol, and $o$-methylphenol by the RHF/3-21G and RHF/6-31G methods. 
All calculations were carried out with PC GAMESS software package $[22,23]$ based on the GAMESS US program package [22]. Data processing and graphical representation of molecular orbitals for conformers of calixarenes were fulfilled with Molekel software [24].

The energies of cooperative hydrogen bonds in calix[4]arene and calix[6]arene were calculated by the procedure suggested by P. Grootenhuis [1] and applied previously [12]. At first we determined the energy of the neutral compound relative to the energy of the monoanion obtained by proton elimination from the optimized neutral structure of the cone conformer of calix[4]arene or compressed cone conformer of calix[6]arene and subsequently optimized with the same level of accuracy as for the neutral conformer $\left(\mathrm{Grad}_{\mathrm{RMS}}=10^{-6} \mathrm{Hartree} / \mathrm{Bohr}\right): \Delta E_{1}=E_{1}$ (calixarene) $-E_{2}$ (calixarene monoanion). Then optimization was performed for phenol and phenoxide anion, and the energy of phenol relative to the energy of the anion was determined: $\Delta E_{2}=E_{3}$ (phenol) $-E_{4}$ (phenoxide anion). The energy $\Delta E_{1}$ is variation of hydrogen bonding and simultaneously charge redistribution (delocalization) in the monoanion. The energy $\Delta E_{2}$, however, is charge delocalization alone in the absence of hydrogen bonding. Consequently, according to this method, the difference between the relative energies $\Delta E_{1}$ and $\Delta E_{2}$ that equals $\Delta \Delta E$ must define variation of the energy of hydrogen bonding.

\section{DISCUSSION OF RESULTS}

Our RHF/STO-2G [13] and RHF/3-21G ab initio calculations predict that the $C_{4}$ cone is the most stable conformer of calix[4]arene (Fig. 2a) and that the $C_{2}$ compressed cone is the most stable conformer of calix[6]arene (Fig. 2b). These results agree with the experimental data of ${ }^{1} \mathrm{H}$ NMR studies of solutions [3] and XRD studies of crystals [3]. On the other hand, inversion of cone type conformers in calix[4]arene and calix[6]arene occurs quite readily at temperatures close to normal conditions $(300 \mathrm{~K})$, the conformational changes in calix[6]arene being much easier than those in calix[4]arene [3]. Nevertheless, other conformations of calix[6]arene are not treated in this paper since their contributions are very low (from $0.00001 \%$ to $1 \%$ ) according to Boltzmann's energy distributions of conformers and we do not intend to discuss large numbers of conformations (from 20 to 100 and more) here.

TABLE 2. Structural Parameters of the Cone Conformer of Calix[4]arene as Calculated by the Density Functional Methods

\begin{tabular}{c|c|c|c|c|c|c|c}
\hline \multirow{2}{*}{$\begin{array}{c}\text { Bond length, } \AA, \\
\text { angle, deg }\end{array}$} & \multicolumn{7}{|c}{ Calculation procedure } \\
\cline { 2 - 7 } & $\begin{array}{c}\text { G96LYP/3- } \\
21 \mathrm{G}\end{array}$ & $\begin{array}{c}\text { CPBE96/3- } \\
21 \mathrm{G}\end{array}$ & $\begin{array}{c}\text { PBE96/3- } \\
21 \mathrm{G}\end{array}$ & BLYP/3-21G & BLYP/6-31G & $\begin{array}{c}\text { B3LYP/3- } \\
21 \mathrm{G}\end{array}$ & $\begin{array}{c}\text { B3LYP/6- } \\
31 \mathrm{G}\end{array}$ \\
\hline $\mathrm{C}_{1}-\mathrm{C}_{2}$ & 1.416 & 1.371 & 1.413 & 1.417 & 1.420 & 1.405 & 1.409 \\
$\mathrm{C}_{1}-\mathrm{C}_{6}$ & 1.415 & 1.371 & 1.413 & 1.416 & 1.419 & 1.404 & 1.407 \\
$\mathrm{C}_{2}-\mathrm{C}_{3}$ & 1.408 & 1.369 & 1.406 & 1.409 & 1.414 & 1.399 & 1.404 \\
$\mathrm{C}_{2}-\mathrm{C}_{7}$ & 1.540 & 1.494 & 1.529 & 1.541 & 1.542 & 1.529 & 1.530 \\
$\mathrm{C}_{1}-\mathrm{O}_{1}$ & 1.411 & 1.361 & 1.404 & 1.414 & 1.417 & 1.400 & 1.401 \\
$\mathrm{O}_{i} \ldots \mathrm{O}_{i+1}$ & 2.483 & 2.454 & 2.453 & 2.499 & 2.583 & 2.494 & 2.574 \\
$\mathrm{C}_{1}-\mathrm{C}_{2}-\mathrm{C}_{3}$ & 118.4 & 118.6 & 118.6 & 118.4 & 117.6 & 118.5 & 117.7 \\
$\mathrm{C}_{1}-\mathrm{C}_{2}-\mathrm{C}_{7}$ & 121.2 & 120.9 & 120.8 & 121.2 & 122.3 & 121.2 & 122.2 \\
$\mathrm{C}_{1}-\mathrm{C}_{6}-\mathrm{C}_{7}$ & 120.7 & 120.2 & 120.5 & 120.6 & 121.5 & 120.5 & 121.4 \\
$\mathrm{C}_{2}-\mathrm{C}_{7}-\mathrm{C}_{6}$ & 113.1 & 111.1 & 112.2 & 112.7 & 114.6 & 112.5 & 114.3 \\
$\mathrm{C}_{2}-\mathrm{C}_{1}-\mathrm{C}_{6}$ & 121.3 & 121.3 & 121.1 & 121.3 & 122.3 & 121.2 & 122.3 \\
$\mathrm{O}_{1}-\mathrm{C}_{1}-\mathrm{C}_{2}$ & 120.4 & 120.8 & 120.1 & 120.5 & 120.6 & 120.7 & 120.7 \\
$\mathrm{O}_{1}-\mathrm{C}_{1}-\mathrm{C}_{6}$ & 118.3 & 117.9 & 118.8 & 118.2 & 117.0 & 118.0 & 117.0
\end{tabular}


TABLE 3. Structural Parameters of the Compressed Cone Conformer of Calix[6]arene

\begin{tabular}{|c|c|c|c|c|c|c|c|c|c|}
\hline \multirow{2}{*}{$d, \AA$} & \multicolumn{4}{|c|}{ Calculation procedure (RHF/) } & \multirow{2}{*}{ Angle, deg } & \multicolumn{4}{|c|}{ Calculation procedure (RHF/) } \\
\hline & STO-2G & $3-21 G$ & $6-31 G$ & PM3 & & STO-2G & $3-21 G$ & $6-31 \mathrm{G}$ & PM3 \\
\hline $\mathrm{C}_{11}-\mathrm{C}_{21}$ & 1.414 & 1.388 & 1.394 & 1.408 & $\mathrm{C}_{11}-\mathrm{C}_{21}-\mathrm{C}_{31}$ & 118.2 & 118.2 & 117.5 & 118.3 \\
\hline $\mathrm{C}_{12}-\mathrm{C}_{22}$ & 1.418 & 1.388 & 1.394 & 1.409 & $\mathrm{C}_{12}-\mathrm{C}_{22}-\mathrm{C}_{32}$ & 118.2 & 118.3 & 117.6 & 118.4 \\
\hline $\mathrm{C}_{13}-\mathrm{C}_{23}$ & 1.417 & 1.390 & 1.395 & 1.408 & $\mathrm{C}_{13}-\mathrm{C}_{23}-\mathrm{C}_{33}$ & 118.4 & 118.3 & 117.6 & 118.6 \\
\hline $\mathrm{C}_{11}-\mathrm{C}_{61}$ & 1.416 & 1.387 & 1.392 & 1.410 & $\mathrm{C}_{11}-\mathrm{C}_{21}-\mathrm{C}_{71}$ & 121.3 & 120.9 & 121.9 & 123.0 \\
\hline $\mathrm{C}_{12}-\mathrm{C}_{62}$ & 1.419 & 1.389 & 1.394 & 1.411 & $\mathrm{C}_{12}-\mathrm{C}_{22}-\mathrm{C}_{72}$ & 122.8 & 121.0 & 122.1 & 123.0 \\
\hline $\mathrm{C}_{13}-\mathrm{C}_{63}$ & 1.418 & 1.390 & 1.394 & 1.408 & $\mathrm{C}_{13}-\mathrm{C}_{23}-\mathrm{C}_{73}$ & 122.0 & 121.5 & 122.3 & 121.6 \\
\hline $\mathrm{C}_{21}-\mathrm{C}_{31}$ & 1.402 & 1.385 & 1.391 & 1.395 & $\mathrm{C}_{11}-\mathrm{C}_{61}-\mathrm{C}_{71}$ & 118.6 & 120.2 & 121.1 & 122.1 \\
\hline $\mathrm{C}_{22}-\mathrm{C}_{32}$ & 1.403 & 1.387 & 1.392 & 1.396 & $\mathrm{C}_{12}-\mathrm{C}_{62}-\mathrm{C}_{72}$ & 119.1 & 120.2 & 121.1 & 121.9 \\
\hline $\mathrm{C}_{23}-\mathrm{C}_{33}$ & 1.402 & 1.386 & 1.391 & 1.393 & $\mathrm{C}_{13}-\mathrm{C}_{63}-\mathrm{C}_{73}$ & 120.0 & 120.8 & 121.4 & 122.4 \\
\hline $\mathrm{C}_{21}-\mathrm{C}_{71}$ & 1.543 & 1.525 & 1.524 & 1.501 & $\mathrm{C}_{21}-\mathrm{C}_{71}-\mathrm{C}_{61}$ & 115.4 & 113.1 & 115.4 & 112.7 \\
\hline $\mathrm{C}_{22}-\mathrm{C}_{72}$ & 1.545 & 1.525 & 1.525 & 1.499 & $\mathrm{C}_{22}-\mathrm{C}_{72}-\mathrm{C}_{62}$ & 116.4 & 117.1 & 118.9 & 115.1 \\
\hline $\mathrm{C}_{23}-\mathrm{C}_{73}$ & 1.546 & 1.530 & 1.528 & 1.501 & $\mathrm{C}_{23}-\mathrm{C}_{73}-\mathrm{C}_{63}$ & 114.5 & 113.2 & 115.5 & 111.4 \\
\hline $\mathrm{C}_{11}-\mathrm{O}_{1} *$ & 1.382 & 1.381 & 1.380 & 1.368 & $\mathrm{C}_{21}-\mathrm{C}_{11}-\mathrm{C}_{61}$ & 120.7 & 121.8 & 122.6 & 121.2 \\
\hline $\mathrm{C}_{12}-\mathrm{O}_{2}$ & 1.383 & 1.380 & 1.378 & 1.367 & $\mathrm{C}_{22}-\mathrm{C}_{12}-\mathrm{C}_{62}$ & 120.2 & 121.6 & 122.3 & 120.8 \\
\hline $\mathrm{C}_{13}-\mathrm{O}_{3}$ & 1.390 & 1.386 & 1.383 & 1.374 & $\mathrm{C}_{23}-\mathrm{C}_{13}-\mathrm{C}_{63}$ & 120.3 & 121.7 & 122.5 & 121.3 \\
\hline $\mathrm{O}_{6} \ldots \mathrm{O}_{1}$ & 2.396 & 2.542 & 2.636 & 2.728 & $\mathrm{O}_{1}-\mathrm{C}_{11}-\mathrm{C}_{21}$ & 123.4 & 120.9 & 120.9 & 123.4 \\
\hline $\mathrm{O}_{1} \ldots \mathrm{O}_{2}$ & 2.397 & 2.521 & 2.596 & 2.735 & $\mathrm{O}_{2}-\mathrm{C}_{12}-\mathrm{C}_{22}$ & 124.3 & 121.0 & 121.1 & 123.2 \\
\hline $\mathrm{O}_{2} \ldots \mathrm{O}_{3}$ & 2.401 & 2.506 & 2.589 & 2.640 & $\mathrm{O}_{3}-\mathrm{C}_{13}-\mathrm{C}_{23}$ & 122.6 & 120.7 & 120.7 & 122.0 \\
\hline $\mathrm{O}_{1}-\mathrm{H}_{1}$ & 1.049 & 1.000 & 0.969 & 0.961 & $\mathrm{O}_{1}-\mathrm{C}_{11}-\mathrm{C}_{61}$ & 115.9 & 117.3 & 116.5 & 115.5 \\
\hline $\mathrm{O}_{2}-\mathrm{H}_{2}$ & 1.047 & 1.007 & 0.973 & 0.960 & $\mathrm{O}_{2}-\mathrm{C}_{12}-\mathrm{C}_{62}$ & 115.6 & 117.4 & 116.6 & 116.0 \\
\hline $\mathrm{O}_{3}-\mathrm{H}_{3}$ & 1.047 & 1.007 & 0.972 & 0.964 & $\mathrm{O}_{3}-\mathrm{C}_{13}-\mathrm{C}_{63}$ & 117.0 & 117.6 & 116.8 & 116.7 \\
\hline $\mathrm{H}_{1} \ldots \mathrm{O}_{6}$ & 1.355 & 1.548 & 1.675 & 1.795 & $\mathrm{O}_{6} \ldots \mathrm{H}_{1}-\mathrm{O}_{1}$ & 170.3 & 171.5 & 170.9 & 162.6 \\
\hline $\mathrm{H}_{2} \ldots \mathrm{O}_{1}$ & 1.352 & 1.515 & 1.623 & 1.788 & $\mathrm{O}_{1} \ldots \mathrm{H}_{2}-\mathrm{O}_{2}$ & 175.7 & 176.4 & 178.9 & 168.0 \\
\hline $\mathrm{H}_{3} \ldots \mathrm{O}_{2}$ & 1.360 & 1.514 & 1.647 & 1.811 & $\mathrm{O}_{2} \ldots \mathrm{H}_{3}-\mathrm{O}_{3}$ & 171.4 & 167.4 & 161.9 & 142.1 \\
\hline & & & & & $\mathrm{H}_{6}-\mathrm{O}_{6} \ldots \mathrm{H}_{1}$ & 103.5 & 98.7 & 100.5 & 108.9 \\
\hline & & & & & $\mathrm{H}_{1}-\mathrm{O}_{1} \ldots \mathrm{H}_{2}$ & 122.5 & 121.8 & 121.3 & 128.4 \\
\hline & & & & & $\mathrm{H}_{2}-\mathrm{O}_{2} \ldots \mathrm{H}_{3}$ & 118.2 & 120.9 & 118.1 & 126.1 \\
\hline & & & & & $\mathrm{H}_{6} \mathrm{C}_{16} \mathrm{H}_{1} \mathrm{O}_{1}$ & -128.6 & -131.6 & -134.4 & -121.0 \\
\hline & & & & & $\mathrm{H}_{1} \mathrm{C}_{11} \mathrm{H}_{2} \mathrm{O}_{2}$ & 155.9 & -174.5 & 174.1 & 138.0 \\
\hline & & & & & $\mathrm{H}_{2} \mathrm{C}_{12} \mathrm{H}_{3} \mathrm{O}_{3}$ & -145.7 & -155.0 & -145.5 & -103.8 \\
\hline
\end{tabular}

*The oxygen and hydrogen atoms of hydroxyl groups bear only one index (the number of the corresponding monomer fragment).

TABLE 4. Energies of Calix[4]arene Conformers as Calculated by Ab Initio and Density Functional Methods

\begin{tabular}{c|c|c|c|c}
\hline Calculation procedure & $\begin{array}{c}\text { Cone (total } \\
\text { energy), au }\end{array}$ & $\begin{array}{c}\text { Partial cone } \\
\text { (relative energy } \\
\left.\Delta E^{*}\right), \mathrm{kcal} / \mathrm{mole}\end{array}$ & $\begin{array}{c}1,2 \text {-Alternate } \\
(\Delta E), \mathrm{kcal} / \mathrm{mole}\end{array}$ & $\begin{array}{c}1,3 \text {-Alternate } \\
(\Delta E), \mathrm{kcal} / \mathrm{mole}\end{array}$ \\
\hline RHF/STO-2G & -1316.87524 & 27.8 & 32.9 & 43.0 \\
RHF/3-21G & -1366.17550 & 18.4 & 22.5 & 32.0 \\
B3LYP/6-31G & -1381.20403 & 15.8 & 19.5 & 28.1 \\
B3LYP/6-31G $(d, p) / / \mathrm{B} 3 \mathrm{LYP} / 6-31 \mathrm{G}$ & -1381.58388 & 9.8 & 12.8 & 16.7 \\
$\mathrm{G} 96 \mathrm{LYP} / 3-21 \mathrm{G}$ & -1374.15816 & 24.0 & 28.0 & 42.1 \\
$\mathrm{~B} 3 \mathrm{LYP} / 6-31 \mathrm{G}(d, p) / \mathrm{BLYP} / 6-31 \mathrm{G}(d)[6]$ & -1382.36033 & 10.5 & 18.4 & 17.6
\end{tabular}

*Difference between the energy of the partial cone, 1,2-alternate, and 1,3-alternate conformers, on the one hand, and the cone conformer energy, on the other. 


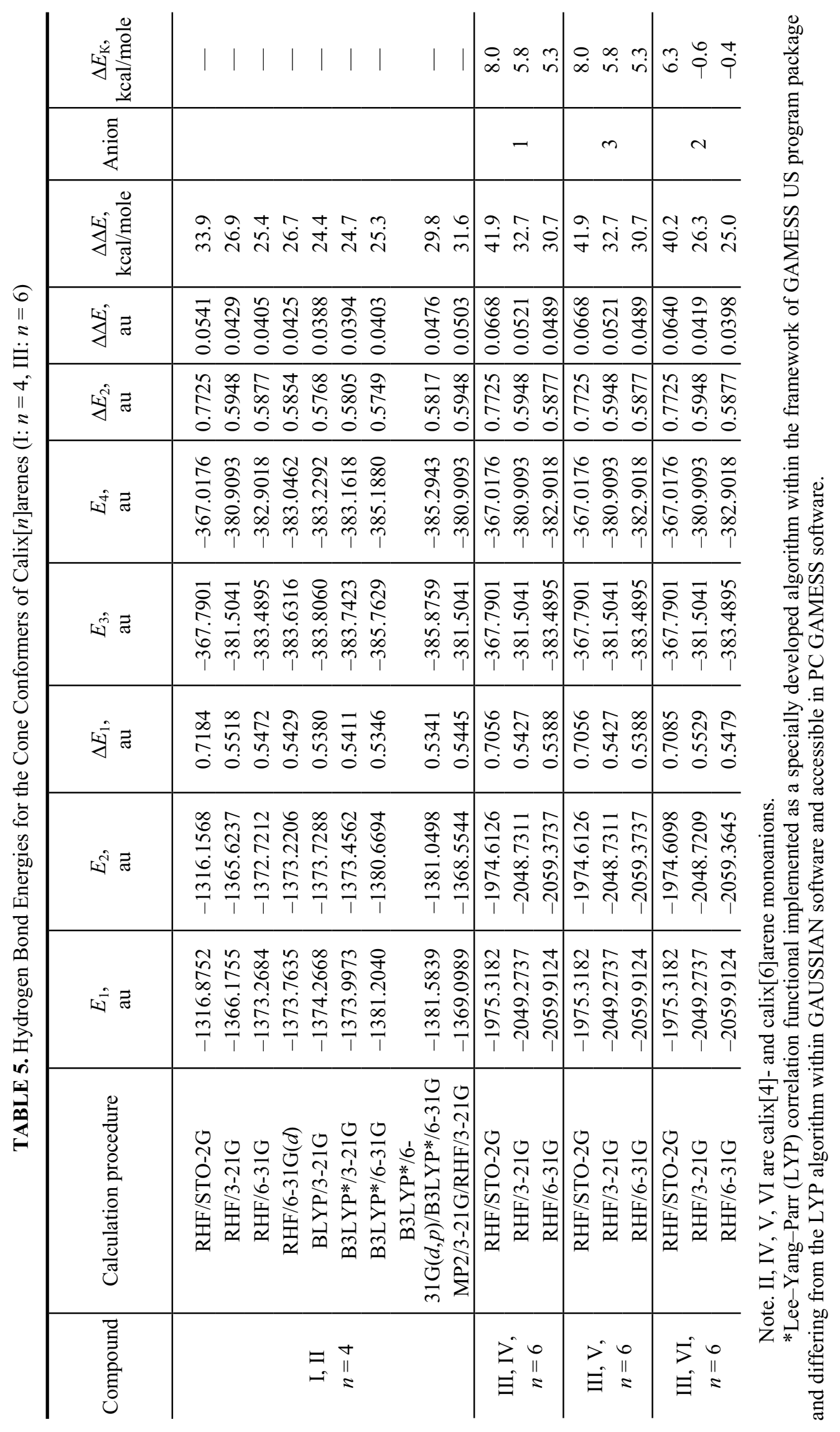


Tables 1, 2, and 3 present the results of geometry optimization for the cone conformers of calix[4]arene (ab initio and density functional methods) and calix[6]arene (ab initio), respectively (for each structural parameter of calix[6]arene, the first line of Table 3 indicates the magnitude of this parameter for the first monomer fragment; the second line, for the second monomer fragment; and the third line, for the third fragment).

As can be seen from the data of Tables 1 and 2, the G96LYP/3-21G, CPBE96/3-21G, and PBE96/3-21G calculated structural parameters of calix[4]arene differ insignificantly from the RHF/STO-2G calculated structural parameters of calix[4]arene (compound I). In view of the high accuracy of the latter method compared with semiempirical and empirical procedures, one can say that all four methods are equally applicable to geometry studies (in the first approximation) on the cone conformation of calix[4]arene. Furthermore, it follows that the three indicated density functional methods using the 3-21G basis are equivalent to the RHF/STO-2G method in overestimating the stability of $\mathrm{H}$ bonds in calix[4]arene; on the other hand, using the G96LYP, CPBE96, and PBE96 functionals in the 3-21G split valence-shell basis fails to improve the results of calculations of the structural parameters of calix[4]arene, including the parameters of $\mathrm{H}$ bonds, compared with the simplest $a b$ initio technique.

The energy difference between the cone and partial cone conformers increases from $15.8 \mathrm{kcal} / \mathrm{mole}(\mathrm{B} 3 \mathrm{LYP} / 6-31 \mathrm{G})$ to $27.8 \mathrm{kcal} / \mathrm{mole}(\mathrm{RHF} / \mathrm{STO}-2 \mathrm{G})$. In ab initio calculations using the $3-21 \mathrm{G}$ basis, this difference also increases from $18.4 \mathrm{kcal} / \mathrm{mole}$ (Hartree-Fock method) to $24.0 \mathrm{kcal} / \mathrm{mole}$ (Gill's and Lee-Yang-Parr's exchange correlation potentials). Using polarization functions in conformer energy calculations decreases substantially the energy difference between all conformers. However, in contrast to the data of [6], all $a b$ initio and density functional methods employed in this work predicted the 1,2-alternate to be much $(4.0 \mathrm{kcal} / \mathrm{mole}$ in the $\mathrm{B} 3 \mathrm{LYP} / 6-31 \mathrm{G}(d, p)$ calculation) more stable than the 1,3-alternate. Moreover, the results of G96LYP/3-21G and RHF/STO-2G calculations demonstrate nearly the same energy picture of conformer stability.

Previously, the RHF/6-31G $(d)$ method was widely employed in hydrogen bond studies [15]. Currently it is still of great interest in studies of calixarenes because these are rather complex objects of investigation that cannot be widely studied by second, third, and fourth order Möller-Plesset methods (especially with full geometry optimization) if calixarenes and their complexes contain large substituents in the upper and/or lower rim. As far as we know, there is only one publication that reports on calculations of calixarene (tetramethoxycalix[4]arene) (again without full geometry optimization) by the second order Möller-Plesset method [8]. Also, note the following: the results of RHF/6-31G(d) and RHF/6-31G calculations of the structural and energy parameters of hydrogen bonding in compound I are quite comparable with one another and with experimental data (see also [6,9]); the experimental values of the energy parameters of hydrogen bonding in calixarenes are yet unknown; RHF/6-31G $(d), \mathrm{RHF} / 6-31 \mathrm{G}(d, p), \mathrm{MP} 2 / 6-31 \mathrm{G}(d)$, and MP2/6-31G $(d, p)$ studies of compound III still present great difficulty.

As can be seen from the data of Tables 1, 2, and 3, calculations on calix[4] arenes using 3-21G, 3-21G $(d, p), 6-31 \mathrm{G}$, and 6-31G $(d)$ bases, as well as calculations on calix[6]arenes using STO-2G, 3-21G, and 6-31G bases, give reliable structural data because the results of these calculations are in reasonable agreement with experimental data (see also [13]).

For compound I, RHF/PM3, RHF/STO-2G, RHF/3-21G, MP2/3-21G//RHF/3-21G (the latter performed by analogy with calculations by Rak, Skurski, Gutowski, et al. [25]), RHF/6-31G, BLYP/3-21G, B3LYP/3-21G, B3LYP/6-31G, MP2/3$21 \mathrm{G}(d) / \mathrm{RHF} / 6-31 \mathrm{G}(d)$, and RHF/6-31G(d)/RHF/STO-2G mixed calculations (6-31G $(d)$ for hydroxyl atoms, and STO-2G for the rest of the calixarene molecule) predicted the following values for variation of the hydrogen bond energy: $20.5 \mathrm{kcal} / \mathrm{mole}$, $33.9 \mathrm{kcal} / \mathrm{mole}, \quad 26.9 \mathrm{kcal} / \mathrm{mole}, \quad 31.6 \mathrm{kcal} / \mathrm{mole}, \quad 25.4 \mathrm{kcal} / \mathrm{mole}, \quad 24.4 \mathrm{kcal} / \mathrm{mole}, \quad 24.7 \mathrm{kcal} / \mathrm{mole}, \quad 25.3 \mathrm{kcal} / \mathrm{mole}$, $30.8 \mathrm{kcal} / \mathrm{mole}$, and $24.8 \mathrm{kcal} / \mathrm{mole}$, respectively. The deviation of these data from the value obtained by RHF $/ 6-31 \mathrm{G}(d)$ $(26.7 \mathrm{kcal} / \mathrm{mole})$ is $\quad-6.2 \mathrm{kcal} / \mathrm{mole}, \quad 7.2 \mathrm{kcal} / \mathrm{mole}, \quad 0.2 \mathrm{kcal} / \mathrm{mole}, \quad 4.9 \mathrm{kcal} / \mathrm{mole}, \quad-1.3 \mathrm{kcal} / \mathrm{mole}, \quad-2.3 \mathrm{kcal} / \mathrm{mole}$, $-2.0 \mathrm{kcal} / \mathrm{mole},-1.4 \mathrm{kcal} / \mathrm{mole}, 4.1 \mathrm{kcal} / \mathrm{mole}$, and $-1.9 \mathrm{kcal} / \mathrm{mole}$, respectively, or $23.2 \%, 27.0 \%, 0.8 \%, 18.4 \%, 4.9 \%, 8.6 \%$, $7.5 \%, 5.2 \%, 15.4 \%$, and $7.1 \%$, respectively. One can conclude that the above-mentioned semiempirical methods (AM1 [1], PM3) and the RHF/6-31G(d)/RHF/STO-2G technique, as well as RHF/STO-2G, RHF/3-21G, and RHF/6-31G, provide information about the magnitude of changes in the $\mathrm{H}$ bond energy in the compounds under study, which is in reasonable agreement with the data of RHF/6-31G(d) calculations (Table 5) [1, 12]. 


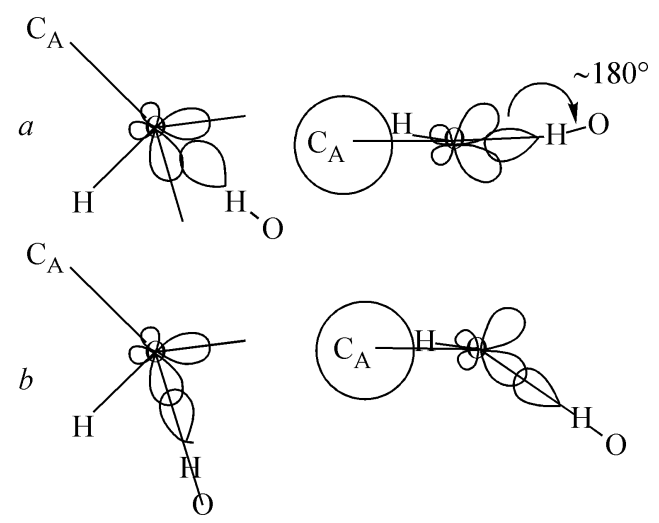

Fig. 3. $\mathrm{O}$ is the tetrahedral $s p^{3}$-hybridized oxygen atom having two lone electron pairs: $a$ - least effective orbital overlap; $b$ - most effective orbital overlap; $\mathrm{C}_{\mathrm{A}}-$ aromatic carbon atom.

The ab initio methods of calculation, where geometry optimization is fulfilled in one approximation and the energy of a structure is calculated in another (in particular, at second order Möller-Plesset level of theory), obviously slightly exaggerate the strength of $\mathrm{H}$ bonds in calix[4]arene; as a result, changes in $\mathrm{H}$ bond energy obtained by these methods approximate the value obtained by RHF/STO-2G. This tendency was also revealed in $[25,26]$.

In calix[4]arene, all four hydrogen bonds are equivalent. For calix[6]arenes, however, both theoretical and experimental investigations revealed three pairs of hydrogen bonds, which differ in their structural characteristics and are generally consistent with $C_{2}$ molecular symmetry [26].

We thought it possible to perform correlation analysis of $\mathrm{H}$ bonding parameters in calix[4]- and calix[6]arenes by analogy with correlation studies of hydrogen bonds for substituted phenols [16]. We evaluated correlation between the $a b$ initio calculated energy parameters of $\mathrm{H}$ bonding and the parameters $d \mathrm{O}_{i} \ldots \mathrm{O}_{i+1}$ (if $i>1$ ) or $d \mathrm{O}_{6} \ldots \mathrm{O}_{1}$. Only those distances $d \mathrm{O}_{i} \ldots \mathrm{O}_{i+1}$ were included that corresponded to slightly changing values of dihedral angles $\angle \mathrm{H}_{i} \mathrm{C}_{1 i} \mathrm{H}_{i+1} \mathrm{O}_{i+1}($ if $i>1)$ or $\angle \mathrm{H}_{6} \mathrm{C}_{16} \mathrm{H}_{1} \mathrm{O}_{1}$ (in the index at the carbon atoms, the first figure is the number of the atom in the benzene ring, and the second figure is the number of the benzene ring). This choice of parameters was dictated by the fact that correlation analysis is senseless if other structural parameters, affecting the energy difference of $\mathrm{H}$ bonding, are varied simultaneously. According to the theory of atomic orbital hybridization, the values of the angles $\angle \mathrm{H}_{i} \mathrm{C}_{1 i} \mathrm{H}_{i+1} \mathrm{O}_{i+1}$ (if $i>1$ ) or $\angle \mathrm{H}_{6} \mathrm{C}_{16} \mathrm{H}_{1} \mathrm{O}_{1}$ define the mutual spatial orientation and overlap efficiency of orbitals involved in strong $[15,27]$ hydrogen bonds (Fig. 3).

In chains of hydrogen bonds, cooperative effects are caused by mutual polarization of these bonds [28]. Therefore, for quantitative evaluation of the effects of adjacent hydrogen bonds on the energies of the bond in question, we examined correlation between the estimated energies of hydrogen bonding (10 values of total energy for molecules and ions used to derive four values of changes in hydrogen bond energies) and the mean values of Mulliken's partial charges on the oxygen atoms of adjacent $\mathrm{H}$ bonds (eight values of Mulliken charge used to derive four means) calculated by the corresponding $a b$ initio methods. The coefficient of correlation between these values obtained by RHF/3-21G and RHF/6-31G is -0.9774 and -0.9990 , respectively. Apart from being evidence of a significant mutual effect of adjacent hydrogen bonds (represented by a linear dependence), this result probably indicates that our method permits correct calculation of changes in the hydrogen bond energy due to cleavage of a definite $\mathrm{H}$ bond in the calixarene molecule (this is also cleavage energy of this bond) called $\mathrm{H}$ bond energy for brevity.

The RHF/STO-2G method predicts that the energy of each hydrogen bond in calix[6]arene will increase compared with its energy in calix[4]arene $\left(\Delta E_{k}\right.$, Table 5). This is indicative of the cooperative effect. The coefficient of correlation between the distances $d \mathrm{O}_{i} \ldots \mathrm{O}_{i+1}\left(d \mathrm{O}_{6} \ldots \mathrm{O}_{1}\right.$ for $\left.i=6\right)$ in calix[4]arene (four $\mathrm{H}$ bonds, $\left.i=1,2\right)$ and calix[6]arene (six $\mathrm{H}$ bonds, 
$i=1,2,3)$ and the energies of the corresponding hydrogen bonds is -0.9977 . At the same time, RHF/3-21G and RHF/6-31G predict decreased binding energies for hydrogen bonds between the second and third and accordingly fifth and fourth monomer fragments in calix[6]arene (Fig. 2b) relative to the energies in calix[4]arene, the difference being $0.6 \mathrm{kcal} / \mathrm{mole}$ $(\mathrm{RHF} / 3-21 \mathrm{G})$ and $0.4 \mathrm{kcal} / \mathrm{mole}(\mathrm{RHF} / 6-31 \mathrm{G})$. This weakening of hydrogen bonding for optimum values of other structural parameters $\left(d \mathrm{H}_{i} \ldots \mathrm{O}_{i+1}\right.$ and $\left.\angle \mathrm{O}_{i+1}-\mathrm{H}_{i+1} \ldots \mathrm{O}_{i}\right)$ may only be explained by the low efficiency of the overlap between the interacting orbitals - lone electron pair of the oxygen atom, on the one hand (nonbonding orbital localized on the oxygen atom in terminology of the MO LCAO method), and the vacant orbitals of the hydrogen atom (vacant orbital mainly localized on the hydrogen atom) involved in the strong $\mathrm{O}_{i+1}-\mathrm{H}_{i+1} \ldots \mathrm{O}_{i}$ hydrogen bonds, on the other. This assumption is supported by the calculated coefficient of multiple correlation [29] between the $\mathrm{H}$ bond cleavage energies obtained in this work and the parameters $\angle \mathrm{H}_{i} \mathrm{C}_{10+i} \mathrm{H}_{i+1} \mathrm{O}_{i+1}\left(\angle \mathrm{H}_{6} \mathrm{C}_{16} \mathrm{H}_{1} \mathrm{O}_{1}\right.$ for $\left.i=6\right)$ and $d \mathrm{H}_{i} \ldots \mathrm{O}_{i+1}\left(d \mathrm{H}_{6} \ldots \mathrm{O}_{1}\right.$ for $\left.i=6\right)$. For these data determined by the RHF/6-31G method, the multiple correlation coefficient is 0.9954 (this coefficient can adopt values from 0 to 1 ). According to $\mathrm{AO}$ hybridization theory, for the given optimum values of $d \mathrm{H}_{i} \ldots \mathrm{O}_{i+1}$ and $\angle \mathrm{O}_{i+1}-\mathrm{H}_{i+1} \ldots \mathrm{O}_{i}$, the orbital overlap will be least effective when the dihedral angle $\angle \mathrm{H}_{i} \mathrm{C}_{1 i} \mathrm{H}_{i+1} \mathrm{O}_{i+1}$ approaches $\pm 180^{\circ}$ (Fig. 3). As can be seen from the data of Table 3, for hydrogen bonds between $\mathrm{O}_{1}$ and $\mathrm{O}_{2}$ (and accordingly between $\mathrm{O}_{4}$ and $\mathrm{O}_{5}$ ), the $\mathrm{H}_{1} \mathrm{C}_{11} \mathrm{H}_{2} \mathrm{O}_{2}$ dihedral angle differs but slightly from $\pm 180^{\circ}\left(\mathrm{RHF} / 3-21 \mathrm{G}: \angle \mathrm{H}_{1} \mathrm{C}_{11} \mathrm{H}_{2} \mathrm{O}_{2}=-174.5^{\circ}\right.$; RHF/6-31G: $\angle \mathrm{H}_{1} \mathrm{C}_{11} \mathrm{H}_{2} \mathrm{O}_{2}=174.1^{\circ}$ ). Along with the large macrocycle and cavity in calix[6]arene relative to those in calix[4]arene, this result of ab initio calculations accounts for the fact that calix[6]arenes are conformationally labile compounds (easily undergo conformational changes) compared with calix[4]arenes, although XRD, as well as structural and energy data, point to the cooperative effect (manifested as shorter distances $d \mathrm{H}_{i} \ldots \mathrm{O}_{i+1}$ and $d \mathrm{O}_{i} \ldots \mathrm{O}_{i+1}$ in calix[6]arene relative to the same distances in calix[4]arene) [13]. Moreover, based on the results of ab initio calculations and in view of the cooperative effect increasing (or decreasing) with the chain of $\mathrm{H}$ bonds, one can conclude that the cycle of $\mathrm{H}$ bonds will decompose by initial cleavage of the weakest hydrogen bonds $\mathrm{O}_{1} \ldots \mathrm{H}_{2}$ $\left(\mathrm{O}_{1} \ldots \mathrm{O}_{2}\right)$ or $\mathrm{H}_{5} \ldots \mathrm{O}_{4}\left(\mathrm{O}_{5} \ldots \mathrm{O}_{4}\right)$ with concurrent weakening of the cooperative effect and stability of other hydrogen bonds [12]. Weakening of hydrogen bonds facilitates further cleavage of other hydrogen bonds during the conformational changes of calix[6]arene.

Formation of an intramolecular $\mathrm{H}$ bond has a strong effect on the dissociation constants of the hydroxy acid, in which the $\mathrm{OH}$ hydrogens are involved in $\mathrm{H}$ bonding. This is explained by stabilization of the initial state (acid) of acid dissociation relative to the conjugate base [30]. The stronger the $\mathrm{H}$ bond, the higher the stability of the initial state and the lower the $K_{\mathrm{a}}$ (the higher the $\mathrm{p} K_{\mathrm{a}}$ ). Consequently, the stability of the intramolecular $\mathrm{H}$ bond may be evaluated from the acid dissociation constant involving the $\mathrm{OH}$ bond that participates in the formation of this $\mathrm{H}$ bond or from the energy difference between the acid and conjugate base. According to this calculation (Table 5), variation of the $\mathrm{OH}$ bond dissociation energy in calix[6]arene compared with calix[4]arene, equal to $\Delta E_{1}$ (calix[6]arene) $-\Delta E_{1}$ (calix[4]arene), exactly coincides with the value of the cooperative effect of hydrogen bonds on passing from calix[4]arene to calix[6]arene.

As follows from Table 5 and Fig. 4, monoanions 1 and 3 are enantiomers (protomers), converted into each other during cleavage of the $\mathrm{H}$ bond between the oxygen atoms of the third and fourth monomer fragments in monoanion 1 and during cleavage of the $\mathrm{H}$ bond between the oxygen atoms of the second and third monomer fragments in monoanion 3, respectively. These anions differ only in the orientation of the stated hydrogen bonds, whose parameters are identical (monoanion 1: $d \mathrm{O}_{3} \ldots \mathrm{O}_{2}=2.771 \AA, \angle \mathrm{O}_{3}-\mathrm{H}_{3} \ldots \mathrm{O}_{2}=149.5^{\circ}, \angle \mathrm{H}_{2} \mathrm{C}_{12} \mathrm{H}_{3} \mathrm{O}_{3}=178.9^{\circ}$; monoanion 3: $d \mathrm{O}_{3} \ldots \mathrm{O}_{4}=2.770 \AA, \angle \mathrm{O}_{3}-$ $\left.\mathrm{H}_{3} \ldots \mathrm{O}_{4}=149.5^{\circ}, \angle \mathrm{H}_{4} \mathrm{C}_{14} \mathrm{H}_{3} \mathrm{O}_{3}=178.9^{\circ}\right)$. Monoanion 2 is at once a protomer and diastereomer of monoanions 1 and 3 and has an achiral configuration.

The change in the hydrogen bond energy during cleavage of one $\mathrm{H}$ bond in the carbon disulfide complex of calix[4]arene is almost equal to that during cleavage of one $\mathrm{H}$ bond in free calix[4]arene molecules (with an accuracy of $0.1 \mathrm{kcal} / \mathrm{mole}$ ); at the same time, the increment of the binding energy for carbon disulfide complex VIII of the calix[4]arene anion relative to that for neutral complex VII is $2.6 \mathrm{kcal} / \mathrm{mole}$ in the RHF/3-21G calculation and $2.0 \mathrm{kcal} / \mathrm{mole}$ in the RHF/6$31 \mathrm{G}$ (MO LCAO) calculation. According to the RHF/6-31G calculation, the bond order between the $\mathrm{S}_{(1)}$ atom lying closest to 

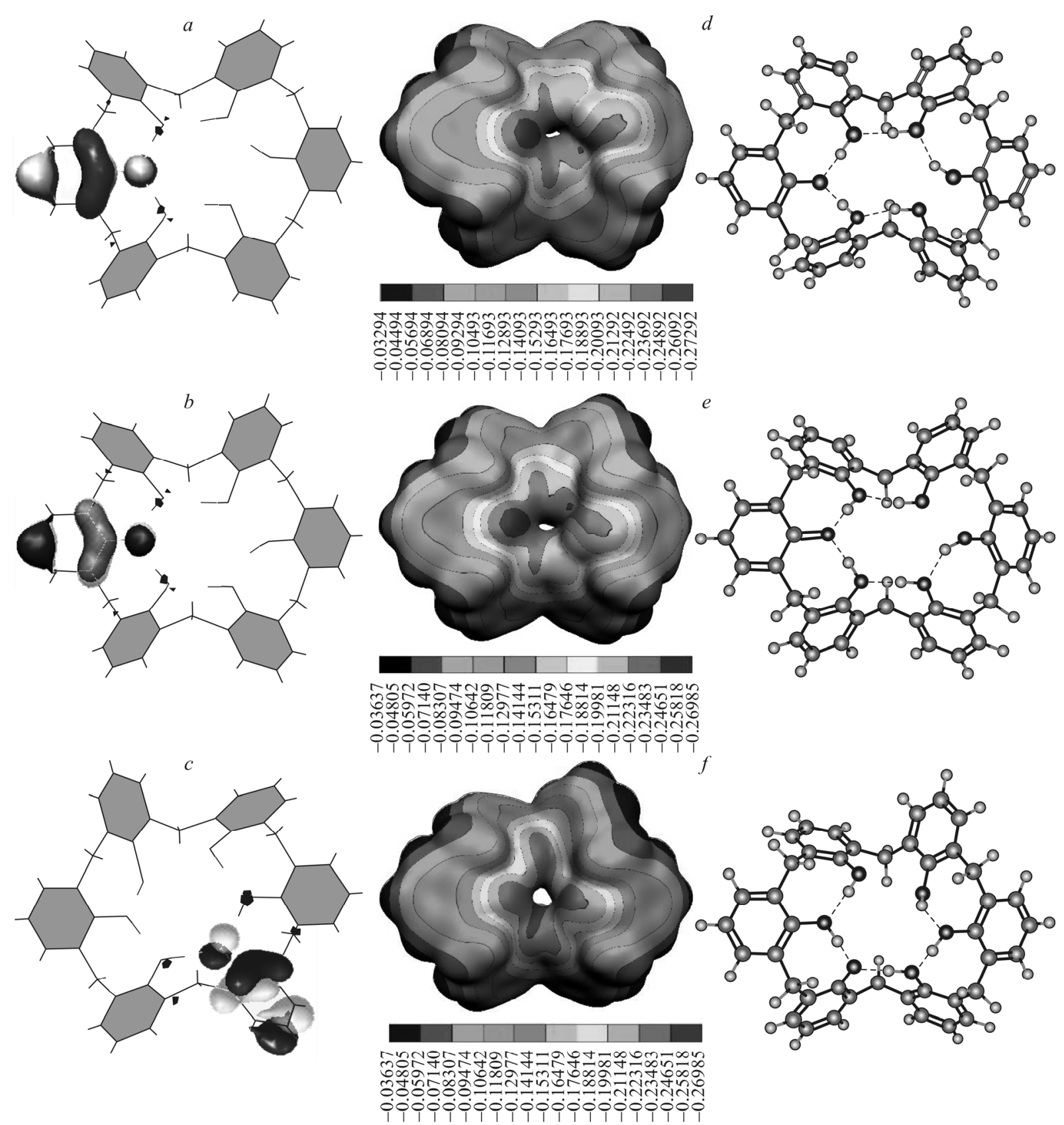

Fig. 4. Calix[6]arene monoanions: $a, b, c-$ HOMOs of monoanions 1, 3, and 2 of calix[6]arene, respectively; $d$, $e, f$ - electrostatic potentials of monoanions 1,3 , and 2 of calix[6]arene, respectively.

the oxygen atoms of calix[4] arene anion II and the carbon atom of $\mathrm{CS}_{2}$ is 1.9 for the bond length $d\left(\mathrm{~S}_{(1)} \mathrm{C}\right)=1.570 \AA$; the bond order between the $\mathrm{S}_{(2)}$ atom and the carbon atom is only 1.6 for the bond length $d\left(\mathrm{~S}_{(2)} \mathrm{C}\right)=1.600 \AA$; and the bond order between the $\mathrm{S}_{(1)}$ and $\mathrm{S}_{(2)}$ atoms is 0.4 for the bond length $d\left(\mathrm{~S}_{(1)} \mathrm{S}_{(2)}\right)=3.171 \AA$. In the free carbon disulfide molecule in vacuum, however, the bond order is the same for both $\mathrm{C}-\mathrm{S}$ bonds (1.6 for bond lengths of $1.579 \AA$ ), while the S-S bond order is the same as that in the calixarene complex ( 0.4 for bond length $3.158 \AA$ ). Along with data on molecular orbitals in the free carbon disulfide molecule and in the carbon disulfide molecule lying in the cavity of calix[4]arene, these values clearly demonstrate that the degenerate energy levels of $\mathrm{C}-\mathrm{S}$ bond electrons in carbon disulfide are split due to complexation with compound I by analogy with the removal of degeneracy of the energy levels in the metal ion lying in the ligand field (according to crystal field theory) [31]. 
As is known, of two identical reaction centers of ambidental nucleophiles, the center with the largest contribution of HOMO or the largest localized negative charge has the highest nucleophilicity [32]. Calixarene monoanions are nucleophiles of this type. According to the RHF/6-31G calculation, from HOMO energy data one can readily see that nucleophilicity decreases in the series: phenol $(-8.63 \mathrm{eV})$, o-methylphenol $(-8.44 \mathrm{eV})$, aniline $(-7.63 \mathrm{eV})$, dimethylaminobenzene $(-7.54 \mathrm{eV})$, benzene $(-9.09 \mathrm{eV})$, and nitrobenzene $(-10.17 \mathrm{eV})$, which is in good agreement with experiment [adiabatic ionization potentials are $-7.14 \pm 0.03 \mathrm{eV}$ (dimethylaminobenzene), $-7.51 \pm 0.03 \mathrm{eV}$ (diethylaminobenzene), or $-7.70 \pm 0.02 \mathrm{eV}$ (aniline), $-8.50 \pm 0.01 \mathrm{eV}$ (phenol), $-8.9 \pm 0.1 \mathrm{eV}$ (o-methylphenol), $-9.247 \pm 0.002 \mathrm{eV}$ (benzene), and $-9.85 \pm 0.03 \mathrm{eV}$ (nitrobenzene), respectively] (experimental data obtained by methods involving the smallest systematic error are indicated [33]). At the same time, it should be taken into account that the experimentally determined values are ionization potentials, while the theoretically calculated values are not adiabatic ionization potentials, requiring extensive computational resources and the use of the unrestricted Hartree-Fock (UHF) method, but HOMO values. This may entail large discrepancies, increasing with the number of substituents in the benzene ring. According to the same calculation technique (RHF/6-31G), the nucleophilicity of o,o-dimethylphenol is almost the same as that of calix[4]arene $\left[E_{\mathrm{HOмо}}(\mathrm{o}, \mathrm{o}-\right.$ dimethylphenol $)=-8.34 \mathrm{eV}, E_{\mathrm{HOMо}}(\mathrm{calix}[4] \operatorname{arene})=$ $-8.33 \mathrm{eV}]$; the difference between the HOMOs of these compounds is $\Delta E_{\mathrm{HOMO}}(\mathrm{o}, \mathrm{o}-$ dimethylphenol, calix[4]arene $)=$ $0.01 \mathrm{eV}$ ), and the nucleophilicity of calix[6]arene is higher than that of calix[4]arene, the difference being very insignificant: $E_{\text {номо }}($ calix[6]arene $)=-8.28 \mathrm{eV}, \Delta E_{\mathrm{HOMO}}(\mathrm{o}, \mathrm{o}-$ dimethylphenol, $\quad$ calix[6]arene $)=0.05 \mathrm{eV} . \quad$ At the same time, the nucleophilicity of the o,o-dimethylphenol anion $\left(E_{\mathrm{HO} о}(\mathrm{o}, \mathrm{o}-\right.$ dimethylphenol anion $\left.)=-1.86 \mathrm{eV}\right)$ is much higher than that of calix[4]arene and calix[6]arene monoanions $\left(E_{\mathrm{Hомо}}\left(\right.\right.$ calix[4]arene monoanion) $=-4.21 \mathrm{eV}, E_{\mathrm{Hомо}}($ calix[6]arene monoanions 1 and 3$)=-4.77 \mathrm{eV}, E_{\mathrm{HOмо}}($ calix[6]arene monoanion 2$)=-4.76 \mathrm{eV}, \Delta E_{\mathrm{HO} о}(\mathrm{o}, \mathrm{o}-$ dimethylphenol anion, calix[4]arene monoanion $)=2.35 \mathrm{eV}, \Delta E_{\mathrm{Hомо}}(\mathrm{o}, \mathrm{o}-$ dimethylphenol anion, calix[6]arene monoanions 1 and 3$)=2.91 \mathrm{eV}, \Delta E_{\mathrm{Hомо}}(\mathrm{o}, \mathrm{o}-$ dimethylphenol anion, calix[6]arene monoanion 2) $=2.90 \mathrm{eV})(\mathrm{RHF} / 6-31 \mathrm{G}$ data). This may be explained by the fact that calixarene monoanion molecules are stabilized by the cooperative system of intramolecular hydrogen bonds, which is only partially weakened by proton elimination, while in the o,o-dimethylphenol anion, intramolecular $\mathrm{H}$ bonds are absent, and stabilization is impossible.

As is known, the proportions of charge and orbital control differ between reactions; the reactivities of molecules and the relative activities of reagents depend on the type of reaction, partner, and medium; and solvation effects cannot be included in gas-phase calculations with sufficient accuracy. Nevertheless, based on the electrostatic potentials in these monoanions and on the clear distribution of the HOMO contribution in calix[6]arene monoanions 1-3, (Fig. 4) (HOMO localization on the phenol fragment that bears the largest partial negative charge) one can draw the following conclusion. In reactions of these anions, proceeding in nonpolar or low polar aprotic solvents in the presence of weak bases, the charge and orbital factors will favor the electrophilic attack at the same reaction center of the reagent (calixarene monoanion). Furthermore, for certain temperatures under these conditions one can predict intermediate formation of calix[6]arene monoanion 2 (which will be slightly in excess) and further electrophilic attack at the oxygen atoms of the first (or fourth if the symmetry of the compressed cone conformer of calix[6]arene is taken into account) monomer fragment. Monoanions 1 and 3 may also form in this case. However, even in the presence of sufficiently strong bases, an electrophilic attack at the oxygen atoms of the second (or fifth) oxygen atoms of the monomer fragment is least possible [30,32]. Process selectivity in this case is also due to the fact that the weakest hydrogen bond, i.e., the $\mathrm{H}$ bond between the oxygen atom of the first monomer fragment and the hydroxyl hydrogen atom of the second monomer fragment, is the first to be broken; based on the symmetry of the conformer, the same also holds for the $\mathrm{H}$ bond between the oxygen atom of the fourth monomer fragment and the hydroxyl hydrogen atom of the fifth monomer fragment.

According to modern generalized interpretation of the Kornblum rule [30], increased positive charge on the reaction center of the substrate leads to a charge-controlled reaction. In this case, the relative reaction rates depend on the net charge on the atoms (for example, on the carbon and oxygen atoms in the enolate ion or on the oxygen atoms of various monomer fragments of calix[6]arene monoanions). On the other hand, the smaller the charge $\delta+$ on the carbon atom of the substrate 
(e.g., of alkyl halide involved in an $S_{N 2}$ nucleophilic substitution reaction), the greater the role of orbital interaction. This leads to nucleophile interacting by an atom having the maximal HOMO coefficient; i.e., in this case we have orbital control. Our present calculation shows that in calix[6]arene monoanion 2, this coefficient is maximal for the oxygen atoms of the first (fourth) monomer fragment, while in monoanions 1 and 3, the HOMO coefficient is maximal for the oxygen atoms of the third (sixth) monomer fragment. Consequently, under conditions of orbital control and in the presence of weak bases in nonpolar or low polar aprotic solvents and in the gas phase, the nucleophilic substitution reaction will occur by an attack at the reaction center of the substrate by only the oxygen atoms of the first (fourth) monomer fragment, on the one hand, and the oxygen atoms of the third (sixth) monomer fragment, on the other. The reaction that occurs by the first mechanism and involves the oxygen atoms of the first (fourth) monomer fragment will slightly prevail over the reaction by the second mechanism. As a result, the intermediate formed in a larger amount will correspond to an achiral configuration of monoanion 2 [34]. Nevertheless, since the reaction products are also liable to conformational changes along with calix[6]arene itself, it is impossible to judge whether the nucleophilic substitution reaction involving compound III is stereoselective or not without using structural and configuration data for the particular substrate.

Thus one can conclude that two pairs of hydrogen bonds in calix[6]arene possess different structural parameters $\left(d \mathrm{H}_{i} \mathrm{O}_{i+1}, d \mathrm{O}_{i} \mathrm{O}_{i+1}, \angle \mathrm{O}_{i} \mathrm{H}_{i} \mathrm{O}_{i+1}, \angle \mathrm{H}_{i} \mathrm{C}_{1 i} \mathrm{H}_{i+1} \mathrm{O}_{i+1}\right)$, but the same $\mathrm{H}$ bond cleavage energy, while the third pair of $\mathrm{H}$ bonds differs

from the other pairs in both structural and energy parameters. In general, a nucleophilic substitution reaction that involves calix[6]arene and occurs in the presence of weak bases in aprotic solvents or in the gas phase should occur via the diastereomeric transition states [34]. If the substrate has no asymmetric centers, the reaction should form an achiral calix[6]arene as a dominant intermediate.

\section{REFERENCES}

1. P. D. J. Grootenhuis, P. A. Kollman, L. C. Groenen, et al., J. Am. Chem. Soc., 112, 4165-4176 (1990).

2. S. Fischer, P. D. J. Grootenhuis, L. C. Groenen, et al., ibid., 117, 1611-1620 (1995).

3. W. P. van Hoorn, F. C. J. M. van Veggel, and D. N. Reinhoudt, J. Org. Chem., 61, No. 20, 7180-7184 (1996).

4. I. Thondorf and J. Brenn, J. Mol. Struct. (Theochem), 398/399, 307-314 (1997).

5. W. P. van Hoorn, M. G. H. Morshuis, F. C. J. M. van Veggel, and D. N. Reinhoudt, J. Phys. Chem. A, 102, 1130-1138 (1998).

6. R. J. Bernardino and B. J. C. Cabral, ibid., 103, 9080-9085 (1999).

7. J. Schatz, A. C. Backes, and H.-U. Siehl, J. Chem. Soc., Perkin Trans. 2, 609/610 (2000).

8. B. P. Hay, J. B. Nicholas, and D. Feller, J. Am. Chem. Soc., 122, 10083-10089 (2000).

9. R. J. Bernardino and B. J. C. Cabral, J. Mol. Struct. (Theochem), 549, 253-260 (2001).

10. L. Frkanec, A. Visnjevac, B. Kojic-Prodic, and M. Zinic, Chem. Eur. J., 6, No. 3, 442-453 (2000).

11. D. M. Rudkevich, ibid., No. 15, 2679-2686.

12. A. N. Novikov, V. A. Bacherikov, and A. I. Gren, Zh. Strukt. Khim., 42, No. 6, 1806-1096 (2001).

13. A. N. Novikov, V. A. Bacherikov, and A. I. Gren, Zh. Obshch. Khim., 72, No. 9, 1481-1486 (2002).

14. M. I. Ogden, A. L. Rohl, and J. D. Gale, Chem. Commun., 1626/1627 (2001).

15. N. D. Sokolov (ed.), The Hydrogen Bond [in Russian], Nauka, Moscow (1981).

16. P. Lipkowski, A. Koll, A. Karpfen, and P. Wolschann, Chem. Phys. Lett., 360, 256-263 (2002).

17. M. Lozynski, D. Rusinska-Roszak, and H.-G. Mack, J. Phys. Chem. A, 101, No. 8, 1542-1548 (1997).

18. A. D. Becke, Phys. Rev. A, 38, 3098 (1998).

19. P. M. W. Gill, Mol. Phys., 89, 433 (1996).

20. C. Lee, W. Yang, and R. G. Parr, Phys. Rev. B, 37, 785 (1988).

21. J. P. Perdew, K. Burke, and M. Ernzerhof, Phys. Rev. Lett., 77, 3865 (1996). 
22. M. W. Schmidt, K. K. Baldridge, J. A. Boatz, et al., J. Comput. Chem., 14, No. 11, 1347-1363 (1993).

23. A. Granovskii, PC GAMESS Software Package [in Russian], Versions 4.3, 6.3, and 6.4.

24. P. F. Flükiger, Molekel, Molecular Visualization Software, University of Geneva (http://igc.ethz.ch/molekel).

25. J. Rak, P. Skurski, M. Gutowski, et al., J. Phys. Chem. A, 101, 283-292 (1997).

26. N. Iki, N. Morohashi, T. Suzuki, et al., Tetrahedron Lett., 41, 2587-2590 (2000).

27. R. Ludwig, Chem. Phys. Chem., No. 1, 53-56 (2000).

28. P. Schuster and P. Wolschann, Universität Wien (www.tbi.univie.ac.at/ pks/PUBL/99-pks-007.pdf).

29. K. Ebert and H. Ederer, in: Computer Applications in Chemistry, VCH, Weinheim (1989).

30. A. S. Dneprovskii and T. I. Temnikova, Theoretical Principles of Organic Chemistry [in Russian], Khimiya, Leningrad (1991).

31. N. S. Akhmetov, General and Inorganic Chemistry [in Russian], Vysshaya Shkola, Moscow (1988).

32. H. Becker, W. Berger, G. Domschke, E. Fanghanel, et al., Organicum, VEB Deutscher Verlag der Wissenschaften, Berlin (1977).

33. L. V. Gurvich, G. V. Karachevtsev, V. N. Kondratiev, et al., Ionization Potentials, in: Chemical Bond Cleavage Energies. Ionization Potentials and Electron Affinities [in Russian], Nauka, Moscow (1974).

34. M. Nogradi, Stereochemistry. Basic Concepts and Applications, Pergamon, New York (1980). 